\title{
Pengembangan Multimedia Pembelajaran Interaktif untuk Mata Pelajaran Matematika untuk Kelas 5 Sekolah Dasar
}

\author{
Feri Hidayatullah Firmansyah ${ }^{1}$, Sekar Nurul Fajriyah Aldriani², \\ Elsya Roziana Dewi ${ }^{3}$ \\ 1,2,3Program Studi Pendidikan Multimedia, Kampus UPI di Cibiru \\ Universitas Pendidikan Indonesia \\ Jl. Raya Cibiru Km 15 Bandung 40393 \\ Email: feri.firmansyah@upi.edu, sekarnurulfa@upi.edu, elsyaroziana@upi.edu
}

\begin{abstract}
ABSTRAK
Proses pembelajaran selama pandemi menuntut guru untuk lebih interaktif pembuatan media pembelajaran online. Pemerintah telah merancang Kurikulum Darurat Covid, Artinya satuan pendidikan dalam kondisi saat ini dapat memilih salah satu dari beberapa komponen yang dibutuhkan dalam proses pembelajaran yaitu tetap mengacu pada kurikulum nasional, menggunakan kurikulum darurat, atau membuat penyederhanaan kurikulum secara mandiri. Untuk penyederhanaan kurikulum, hanya materi pokok dalam kegiatan pembelajaran yang perlu disampaikan, Sedangkan untuk latihan bisa secara mandiri atau melalui media aplikasi. Penelitian ini bertujuan untuk membuat media pembelajaran berbasis augmented reality bidang geometri pada mata pelajaran matematika untuk kelas 5 sekolah dasar. Media ini dapat memudahkan siswa dalam memahami bentuk augmented reality dan terdapat fitur video pembelajaran yang juga menjelaskan materi yang disajikan oleh guru. Dengan metode black box white box, aplikasi dikembangkan dengan menyesuaikan penyederhanaan kurikulum yang direncanakan oleh pemerintah. Fitur dalam aplikasi tersebut antara lain tujuan dan materi, video pembelajaran, simulasi augmented reality dan terintegrasi dengan Google Kelas sebagai platform evaluasi pembelajaran. Hasil penelitian ini adalah aplikasi yang dapat diakses dari web atau aplikasi android.
\end{abstract}

Kata kunci: Media Pembelajaran, Multimedia Pembelajaran Interaktif, Pembelajaran Jarak Jauh, Pembelajaran Augemented Reality

\section{ABSTRACT}

The learning process during a pandemic requires teachers to be more interactive in making online learning media. The government has designed the Covid Emergency Curriculum, which is that educational units in their current condition can choose one of the several components needed in the learning process, namely still referring to the national curriculum, using the emergency curriculum, or making curriculum simplification independently. For curriculum simplification, only the main material in learning activities needs to be conveyed, while for practice it can be independently or through an application media. This study aims to create an augmented reality-based learning media on geometry in mathematics subjects for grade 5 elementary school. This media can make it easier for students to understand the shapes with augmented reality and there is a learning video feature that also explains the material presented by the teacher. With the black box white box method, the application is developed by adjusting the curriculum simplification planned by the government. Features in the application include objectives and materials, learning videos, augmented reality simulations and integrated with Google Classroom as a learning evaluation platform. The results of this research are applications that can be accessed from the web or android applications.

Keywords: Learning Media, Interactive Learning Multimedia, Distance Learning, Augemented Reality Learning

\section{Pendahuluan}

Proses pembelajaran merupakan upaya yang dilakukan dengan sengaja oleh pendidik untuk menyampaikan ilmu pengetahuan, mengorganisasi dan menciptakan sistem lingkungan dengan berbagai metode sehingga siswa dapat melakukan kegiatan belajar secara efektif dan efisien untuk mendapatkan hasil yang optimal. Dalam menyampaikan materi, guru dihadapkan pada dua hal utama yakni pengelolaan kelas dimana guru harus dapat menciptakan suasana yang kondusif dalam proses pembelajaran supaya tujuan pembelajaran dapat tercapai dan dengan menggunakan metode pembelajaran yang tepat diharapkan guru dapat melakukan kegiatan belajar secara terkontrol dan terarah. 
Salah satu aspek utama yang mendukung dalam proses pembelajaran adalah pemilihan media yang tepat sesuai dengan materi pembelajaran yang disampaikan. Di masa pandemi seperti saat ini proses pembelajaran harus dilaksanakan dari rumah (work from home) yang dimana siswa juga harus mampu untuk belajar baik secara mandiri maupun didampingi oleh orang tuanya. Oleh karena itu proses pembelajaran di masa pandemi mewajibkan pengajar untuk lebih interaktif dalam membuat media pembelajaran dalam jaringan agar materi yang disampaikan sesuai dengan capaian pembelajaran.

Untuk memastikan hak belajar setiap anak terpenuhi, Kemendikbud telah menghadirkan beberapa inisiatif untuk mendukung pelaksanaan belajar dari rumah. Beberapa inisiatif/terobosan tersebut di antaranya adalah pengoptimalan platform pendidikan jarak jauh dan menyiapkan dukungan kebijakan pelaksaan kurikulum di masa khusus, yakni satuan pendidikan dapat 1) tetap menggunakan kurikulum nasional; 2) menggunakan penyederhanaan kurikulum dalam kondisi khusus yang disusun oleh Kemendikbud; dan 3) melakukan penyederhanaan kurikulum secara mandiri. Untuk penyederhanaan kurikulum, materi pokok dalam kegiatan pembelajaran saja yang perlu disampaikan sedangkan untuk praktik bisa secara mandiri atau lewat sebuah media aplikasi.

Salah satu solusi di masa pandemi bagi penyelenggara pendidikan adalah dengan melakukan penyederhanaan kurikulum secara mandiri dimana proses pembelajaran dirangkum ke dalam pembelajaran jarak jauh dan media yang digunakan berbasis dalam jaringan (daring). Penelitian ini bertujuan untuk membuat sebuah media yang dapat membantu siswa dalam belajar secara online dan dapat beradaptasi dengan pembelajaran jarak jauh. Materi yang dirangkum dalam media ini adalah bangun ruang yang diambil dari materi kelas 5 semester 2 sekolah dasar. Dalam media terdapat penyampaian tujuan pembelajaran, materi pembelajaran, simulasi augmented reality, dan terintegrasi dengan LMS Google Classroom sebagai media penghubung pembelajaran untuk pemberian tugas-tugas, maupun diskusi Bersama dengan guru.

\section{Metode Penelitian}

Pengembangan media pembelajaran erat kaitannya dengan kesesuain model dan metode dalam proses pembelajaran. Model pembelajaran yang digunakan adalah model pembelajaran jarak jauh dalam jaringan (daring) dimana model pembelajaran ini diharapkan dapat menyesuaikan dengan kondisi saat ini. Proses pembelajaran yang baik adalah perencanaan yang baik dan media yang sesuai dengan tema pembelajaran. Oleh karena itu agar media pembelajaran yang dikembangkan sesuai dengan topik pembelajaran yakni bangun ruang untuk kelas 5 semester 2 sekolah dasar maka media yang dikembangkan harus sesuai dengan tujuan pembelajaran. Dalam penelitian ini terdapat dua metode yang digunakan yakni Design and Development (DnD) dan Black Box.

\subsection{Metode Design and Development}

Rencana penelitian ini adalah Desain LMS (Learning Management System) dan pengembangan model pembelajaran. Dengan itu DnD digunakan untuk menentukan kesesuaian media terhadap perangkat pembelajaran. Berikut sistematika metode $\mathrm{DnD}$ dalam penelitian ini.

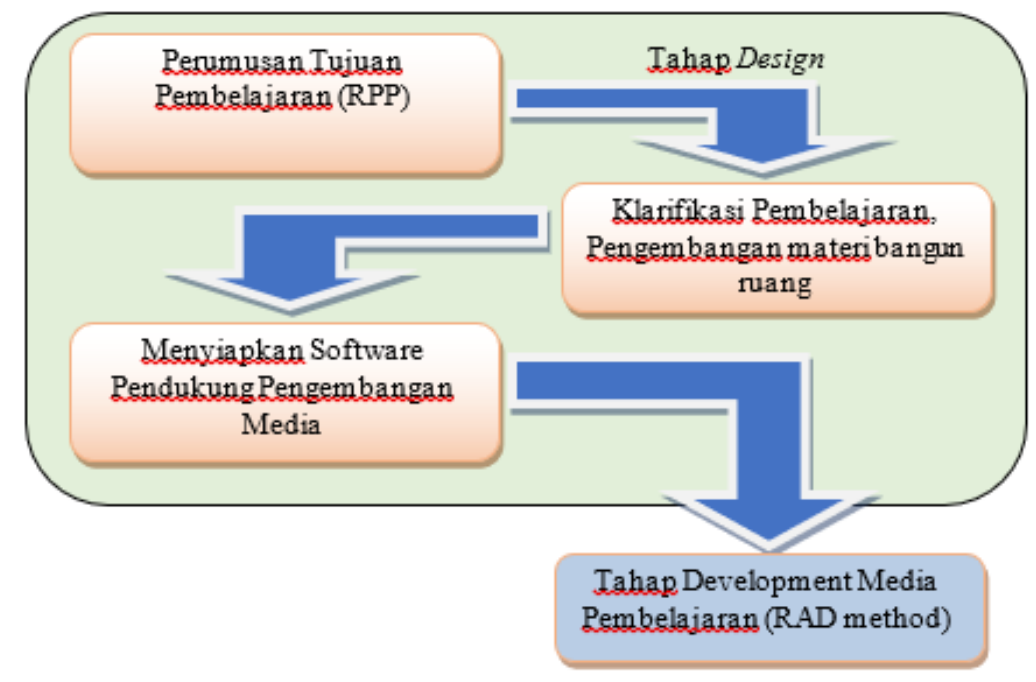

Gambar.1 Metode Penelitian DnD tahap Desain 
Gambar di atas menunjukkan metode $\mathrm{DnD}$ di tahap desain. Perencanaan kebutuhan media harus disesuaikan dengan tujuan pembelajaran maka dari itu perlu desain pembelajaran yang tepat agar media sesuai dengan pembelajaran dan desain yang tidak membuat siswa menjadi bosan dan juga lebih mengarahkan kepada materi tidak kepada desain antar mukanya. Dimulai dengan perumusan tujuan yakni berupa penyesuain materi dengan RPP dimana materi yang dikembangkan dalam pengembangan media ini adalah bangun ruang untuk kelas 5 semester 2 sekolah dasar. Dilanjutkan pada aktifitas terakhir di tahap desain yakni menentukan perangkat lunak untuk mengembangkan media. Pada penelitian ini software yang digunakan adalah berbasis online yakni menggunakan Appgeyser, G-Sites, Google Classroom dan MyWebAR untuk membuat Augmented Reality berbasis online.

Tahap terakhir yaitu tahap Development Media Pembeajaran (RAD method). Metode RAD ini digunakan untuk pengembangan sistem informasi dengan waktu yang singkat. berikut skema tahap developmen menggunakan RAD. Selain itu metode ini mengikuti tahapan pengembangan sistem sepeti umumnya, tetapi mempunyai kemampuan untuk menggunakan kembali komponen yang ada (reusable object) sehingga tidak perlu membuat dari awal lagi dan biaya produksi menjadi lebih rendah dalam menggunakan Rapid Application Development (RAD).

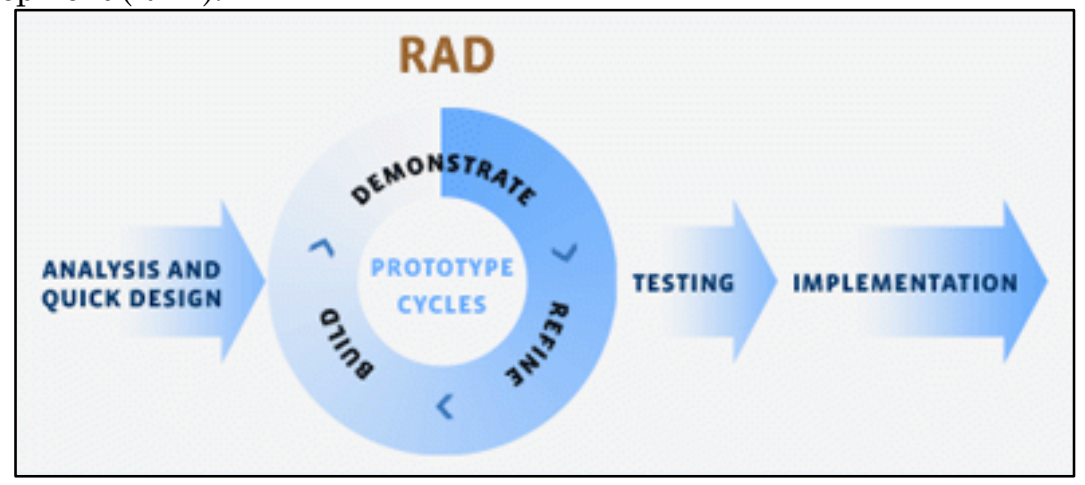

Gambar. 2 Rapid Application Development

Sebenarnya RAD ini digunakan untuk pengerjaan proyek pengembangan aplikasi dalam jangka waktu pendek, sehingga bertujuan untuk mengefisiensi waktu pengembangan aplikasi. Jika semua bagian aplikasi dan materi dianggap sesuai dengan tujuan dan proses pembelajaran maka masuk di tahap testing dan dapat lanjut pada tahap pengimplementasian di kelas untuk menilai media pembelajaran yang sudah dikembangkan.

\subsection{Metode Black Box}

Black box testing adalah pengujian yang dilakukan hanya mengamati hasil eksekusi melalui data uji dan memeriksa fungsional dari perangkat lunak. Black Box pengujian adalah metode pengujian perangkat lunak yang menguji fungsionalitas aplikasi yang bertentangan dengan struktur internal atau kerja. Uji kasus dibangun di sekitar spesifikasi dan persyaratan, yakni, aplikasi apa yang seharusnya dilakukan. menggunakan deskripsi eksternal perangkat lunak, termasuk spesifikasi, persyaratan, dan desain untuk menurunkan uji kasus.

Keuntungan penggunaan metode Blackbox Testing adalah: (1) Penguji tidak perlu memiliki pengetahuan tentang Bahasa pemrograman tertentu; (2) Pengujian dilakukan dari sudut pandang penguna, ini membantu untuk mengungkapkan ambiguitas atau inkositensi dalam spesifikasi persyaratan; (3) Programmer dan tester keduanya saling bergantung satu sama lain.

Kekurangan dari metode Blackbox Testing adalah: (1) Uji kasus sulit desain tanpa spesifikasi yang jelas; (2) Kemungkinan memiliki pengulangan tes yang sudah dilakukan oleh Programmer; (3) beberapa bagian back end tidak diuji sama sekali.

Black box testing yang diterapkan di penelitian ini adalah boundary values analysis yang merupakan suatu Teknik pengujian perangkat lunak dimana tes dirancang untuk mencakup perwakilan dari nilai-nilai batas. Dimana Prinsip kerja BVA yaitu: (1) Kesalahan yang banyak terjadi adalah Ketika proses masukan; (2) BVA bekerja pada proses masukan. Nilai dapat berupa rentang masukan atau keluaran dari komponen perangkat 
lunak. Karena batas-batas tersebut adalah lokasi umum untuk kesalahan yang mengakibatkan kesalahan perangkat lunak mereka sering dilakukan dalam kasus-kasus uji. Hasil pengujian adalah sebagai berikut.

\section{a. Unified Modeling Language (UML)}

Proses pembelajaran dan penggunaan aplikasi dapat ditunjukkan pada gambar Unified Modeling Language (UML) berikut ini.

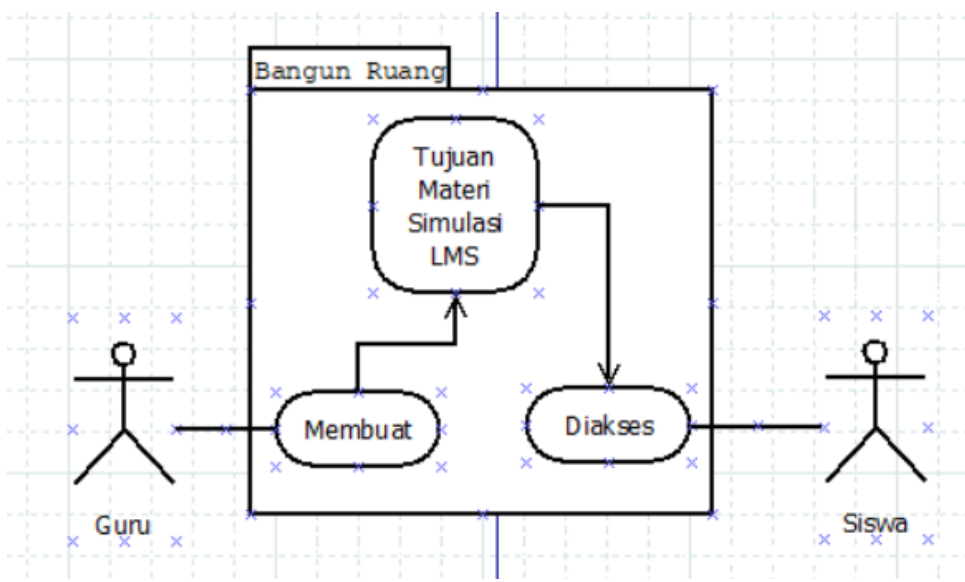

Gambar. 3 Usecase Unified Modeling Language.

Diagram tersebut merepresentasi interaksi antara dua aktor yakni guru yang berperan sebagai pembuat media dan siswa sebagai pengakses media. Dengan menggunakan metode UML akan memudahkan developer sistem dalam merancang sistem yang akan dibuat karena sifatnya yang berorientasikan pada objek. Pada gambar 3 merupakan diagram usecase kegiatan pembelajaran menggunakan LMS Google Classroom. Layanan LMS Google Classroom ini membantu guru dalam memantau kegiatan pembelajaran siswa seperti pengerjaan tugas, diskusi dan kegiatan lainnya. Selain itu dapat memberikan bahan ajar dan interaksi proses belajar dalam berbagai fitur seperti forum, chat, kuis, video.

Learning Management System ini dapat mengelola pembelajaran dalam memberikan sebuah materi, mendukung kolaborasi, menilai kinerja siswa, merekam data peserta didik, dan dihasilkan laporan yang berguna untuk memaksimalkan efektivitas dari sebuah pembelajaran pada pembelajaran bangun ruang. Sehingga mendukung proses belajar, terhubung dengan situs di seluruh dunia sehingga akses perkembangan informasi yang cepat dan akurat dapat diperoleh peserta didik dalam waktu yang singkat, di manapun dan kapanpun.

\section{b. Deskripsi Output yang dihasilkan}

Luaran dari media berbasis digital yang dikembangkan menggunakan $M y W e b A R$ dan google sites sehingga luaran yang dapat diakses oleh siswa adalah berupa buku digital yang ditunjukkan pada gambar berikut.

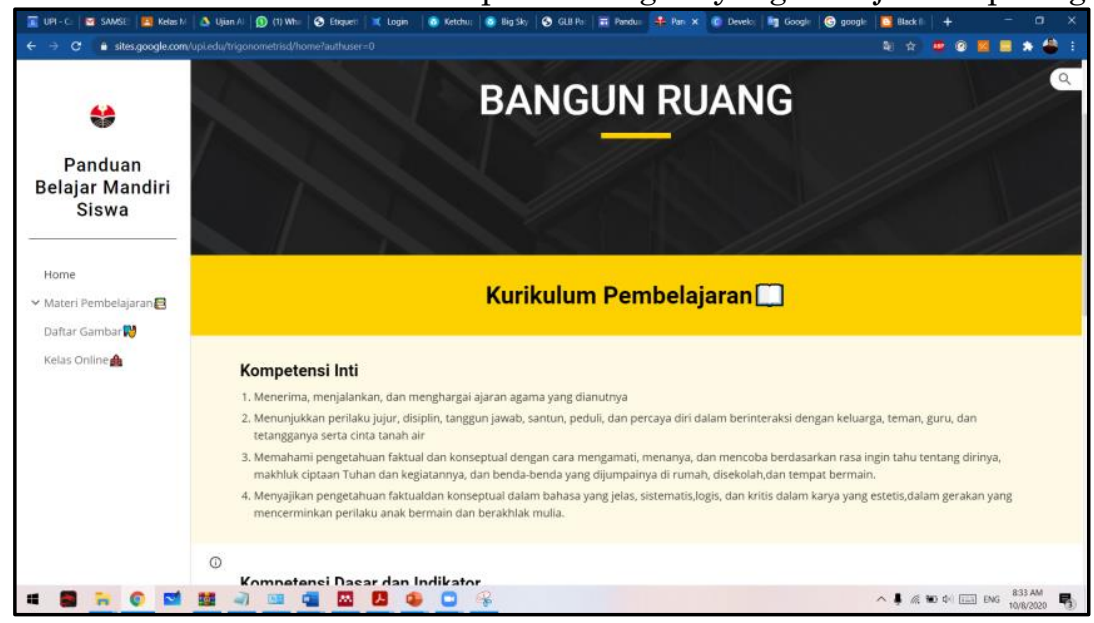

Gambar.4 Buku Digital 
Buku digital dapat diakses di link berikut https://sites.google.com/upi.edu/trigonometrisd/home. Dalam media tersebut terdapat perangkat pembelajaran yang dapat digunakan guru untuk mendampingi dalam proses belajar dan bagi siswa terdapat materi yang dapat dipelajari secara mandiri. Terdapat tujuan pembelajaran, materi yang dipelajari, daftar gambar, dan kelas online yang digunakan sebagai learning management system yang terhubung dengan kelas inti. Selain luaran dalam bentuk buku digital juga terdapat augmented reality di setiap materi untuk menampilkan contoh faktual dari objek bangun ruang yang dipelajari.

\section{c. Deskripsi Output yang digunakan}

Luaran dari pengembangan media ini adalah buku digital dan media augmented reality. Pada buku digital terdapat tujuan pembelajaran yang berada di menu home. Tujuan pembelajaran memuat tujuan, deskripsi dan indicator pembelajaran. Materi pembelajaran yang dipelajari dari media buku digital ini adalah matematika tentang pembahasan bangun ruang, Adapun materi yang dibahas adalah kubus, balok, tabung, limas, kerucut, dan prisma segitiga. Media ini juga menampilkan augmented reaility yang dapat membantu siswa untuk memahami materi bangun ruang yang dipelajari.
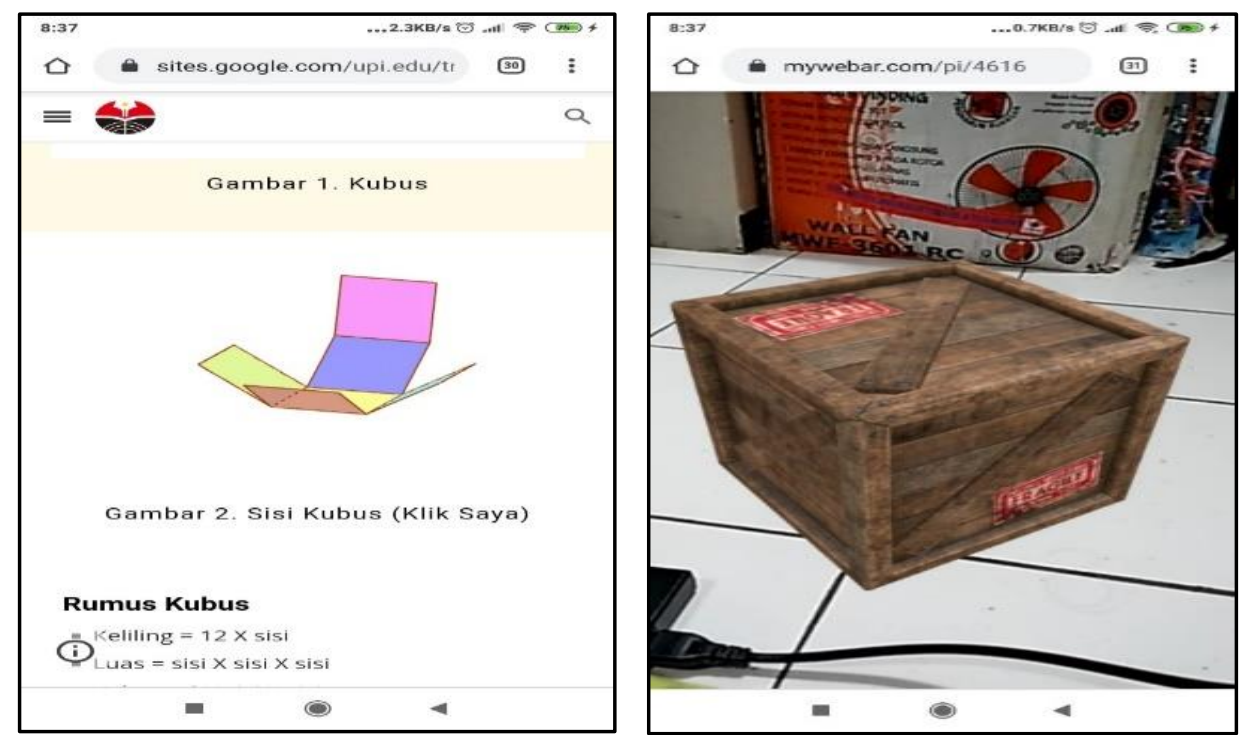

Gambar. 5 Buku Digital

Luaran yang terakhir adalah terhubung dengan google classroom dimana setelah siswa belajar dapat langsung mengerjakan dan mengumpulkan tugas yang diberikan oleh guru di google classroom. Tidak hanya untuk mengerjakan dan mengumpulkan tugas Google Classroom juga dapat menjadi tempat diskusi apabila siswa masih kurang memahami materi yang di sampaikan pada Buku Digital tersebut. Dan Google Classroom juga menjadi salah satu tempat interaksi secara online antara Guru dengan siswa.

\section{d. Kendali terhadap system yang dibuat}

Untuk buku digital ini tidak terlalu membutuhkan banyak perangkat untuk dijalankan tergantung pada perangkat yang digunakan. Buku Digital ini dapat diakses melalui desktop maupun mobile. Apabiala menggunakan di Desktop media ini membutuhkan perangkat control seperti mouse, keyboard untuk mengakses di pencarian, dan kamera untuk menggunakan fitur augmented reality. Apabila di Handphone hanya membutuhkan kamera untuk menjalankan fitur augmented reality.

\section{Hasil dan Diskusi}

Dari pengembangan media didapatkan hasil berupa media pembelajaran dengan mengangkat materi bangun ruang untuk kelas 5 sekolah dasar yang dapat diakses melalui perangkat telepon atau desktop computer. Dengan kemudahan akses ini maka media ini dapat digunakan di setiap perangkat digital secara online. Dengan menggunakan $M y W e b A R$ simulasi citra digital tidak berat untuk dijalankan karena sumber dayanya diakses secara online. Buku digital ini juga dikembangkan dalam bentuk aplikasi android yang dapat dipasang diperangkat telpon supaya siswa dan guru dapat mengakses media belajar dengan mudah dan cepat.

Beberapa perangkat pendukung yang digunakan untuk media pembelajaran tersebut secara online adalah google site sebagai tempat akses buku digital mata pelajaran bangun ruang, google meet untuk simulasi kelas 
antara guru dan siswa dan LMS Google Classroom untuk ruang kelas pembelajaran online dan evalusi guru dan siswa. Untuk memulai pembelajaran siswa menyiapkan software pendukung pengembangan media terlebih dahulu. Setelah itu mengakses buku digital di google sites.

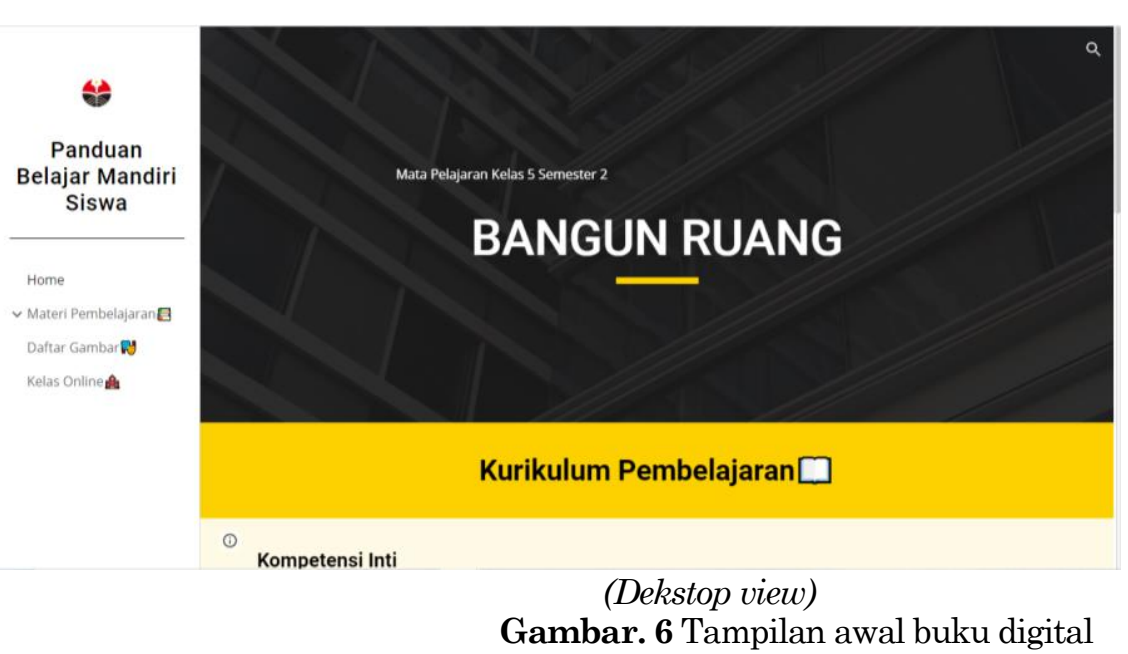

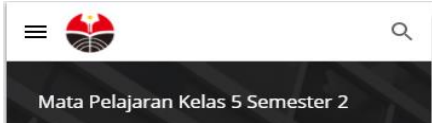

BANGUN RUANG

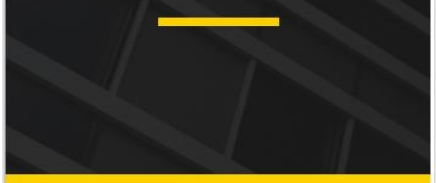

Kurikulum Pembelajaran

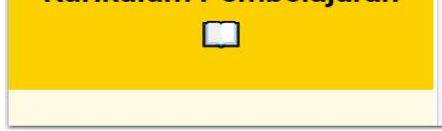

(Mobile View)

Penggunaan google sites sebagai tempat akses buku digital dinilai sebagai media yang kompatibel dan bisa diakses di semua perangkat. Google sites bisa memasukan konten media dalam berbagai bentuk seperti audio, video, gambar dan simulasi citra digital seperti $M y W e b A R$.

Dalam buku digital ini memuat perumusan tujuan pembelajaran (RPP) terdapat kurikulum pembelajaran yang berisi $\mathrm{KI} / \mathrm{KD}$, indikator pembelajaran dan tujuan pembelajaran.

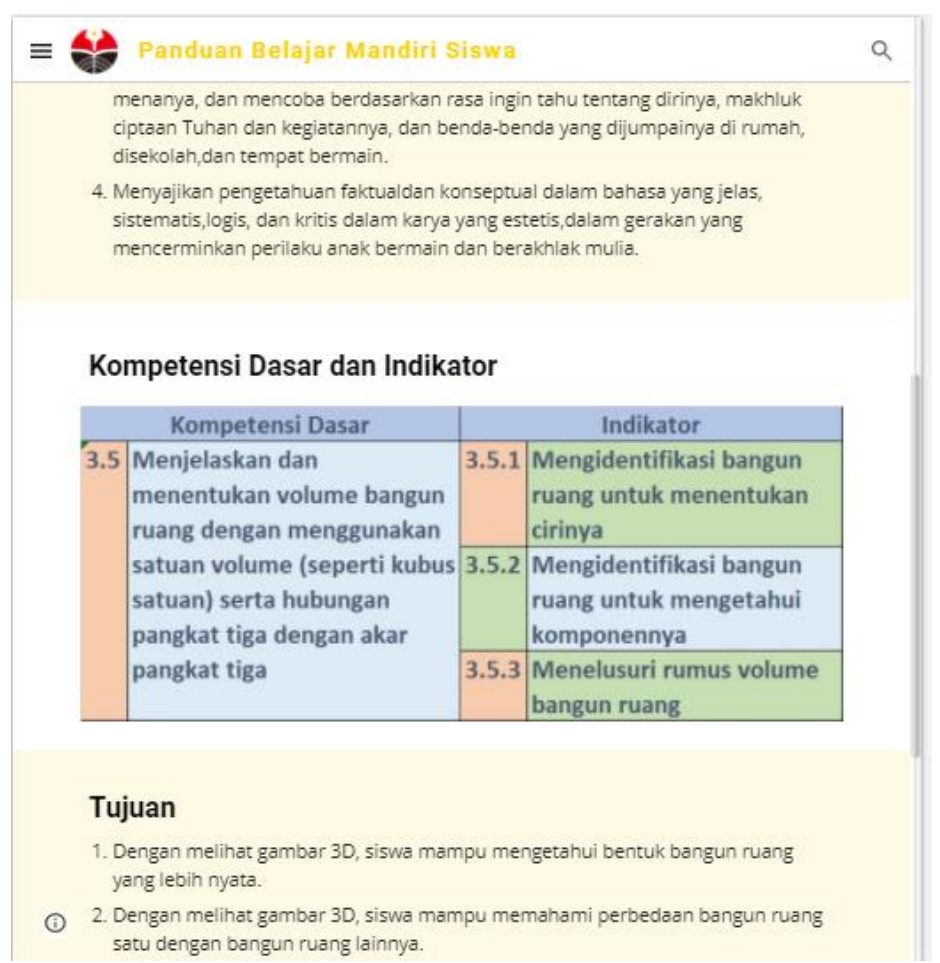

Gambar. 7 Rancangan Pelaksanaan Pelmbelajaran

Pada Bagian Materi Pembelajaran sumber referensi dari Buku pegangan siswa dan guru Kelas 5 Sekolah Dasar, yang mana didalamnya terdapat Materi Kubus, Balok, Tabung, Bola, Limas, Keruvut, Prisma Segitiga, Prisma Segi Lima, dan juga Prisma Segi Enam. 


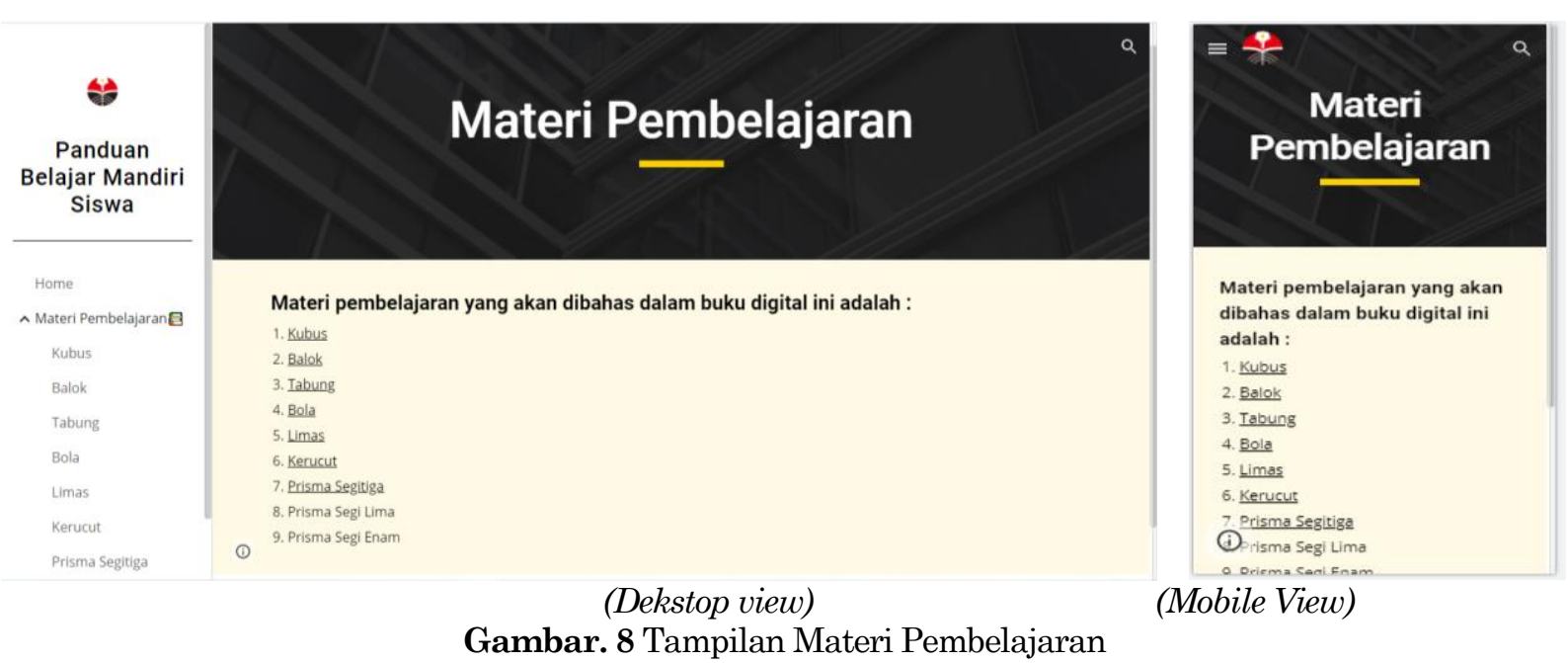

Apabila memilih salah satu materi pembelajaran tersebut seperti contohnya adalah Kubus, didalamnya ini berisi mengenai pengertian Kubus, Gambar Kubus, Ciri-Ciri Kubus, Rumus Kubus disertai dengan JaringJaring Kubus.

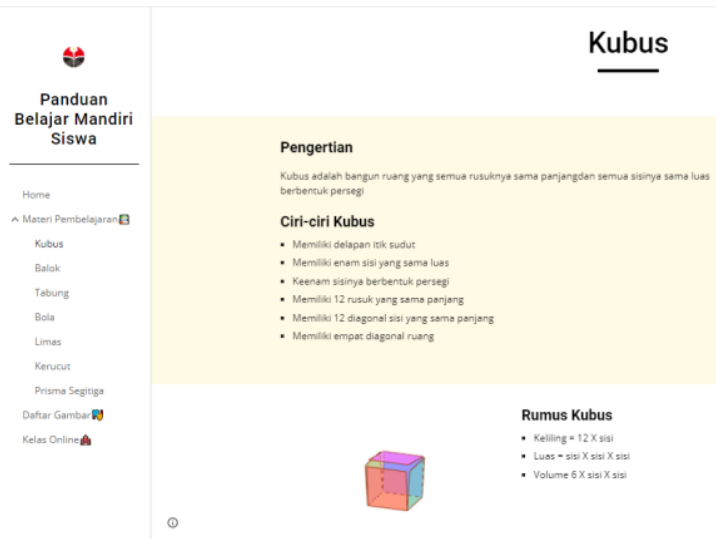

(Dekstop view)

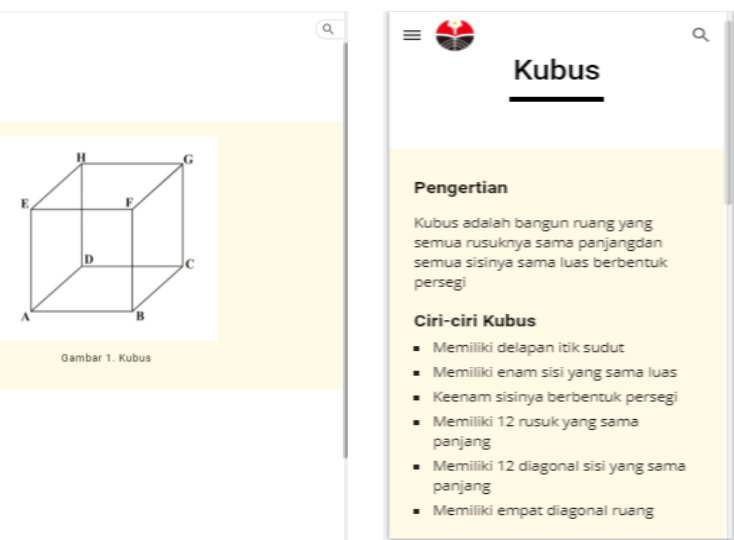

(Mobile View)

Gambar. 9 Tampilan Materi Pembelajaran Kubus

Untuk Menampilkan Augmented Reality pada Bangun Ruang tersebut, dengan cara klik pada bagian Jaringjaring Bangun Ruang tersebut, lalu akan tersambung dengan aplikasi MyWebAR.com, dan arahkan kamera pada baian tempat yang datar untuk memunculkan Augmented Reality Bangun Ruang tersebut.

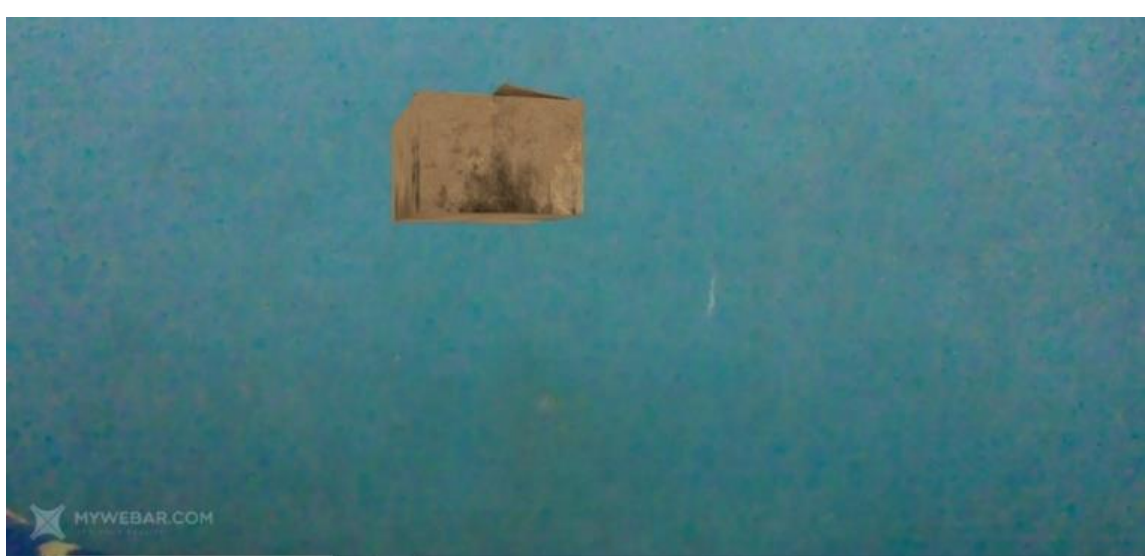

(Dekstop view)

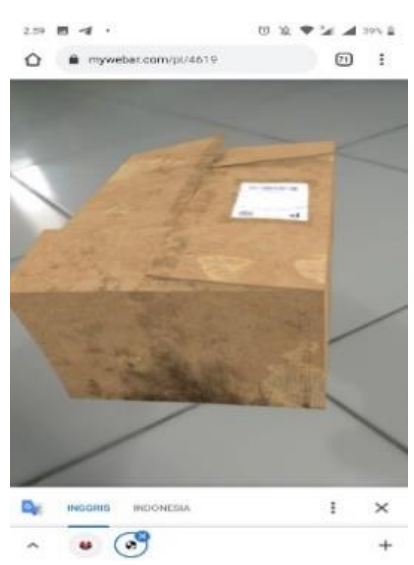

(Mobile View)

Gambar. 10 Tampilan Augmented Reality 
Pada Bagian Daftar Gambar ini memiliki kaitan dengan Materi Pembelajaran, dimana daftar Gambar ini menyesuaikan dengan apa saja bangun ruang yang ada di materi pembelajaran.

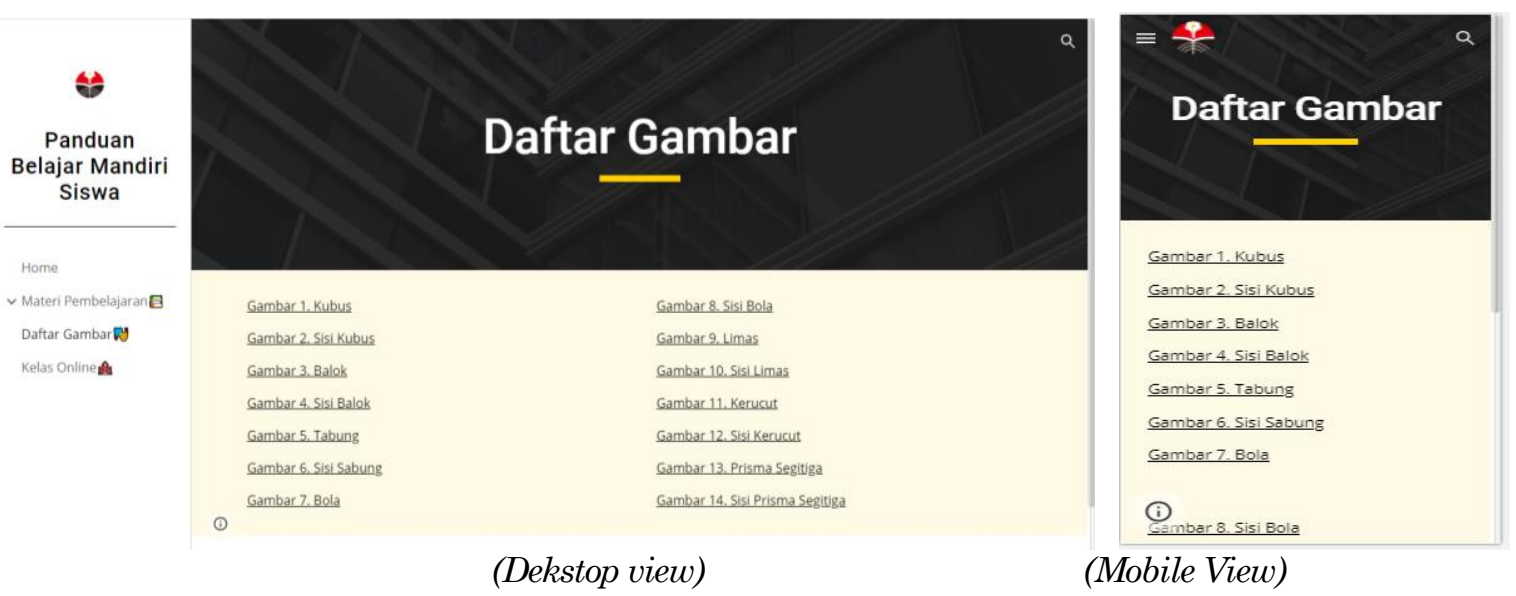

Gambar. 11 Tampilan Daftar Gambar

Pada bagian kelas online di menu buku digital, siswa akan langsung diarahkan untuk bergabung ke Google Classroom sebagai Learning Management System yang mebantu guru dalam memantau segala kegiatan siswa dalam pembelajaran dan siswa dapat mengakses segala kegiatan pembelajaran yang akan dilakukan.

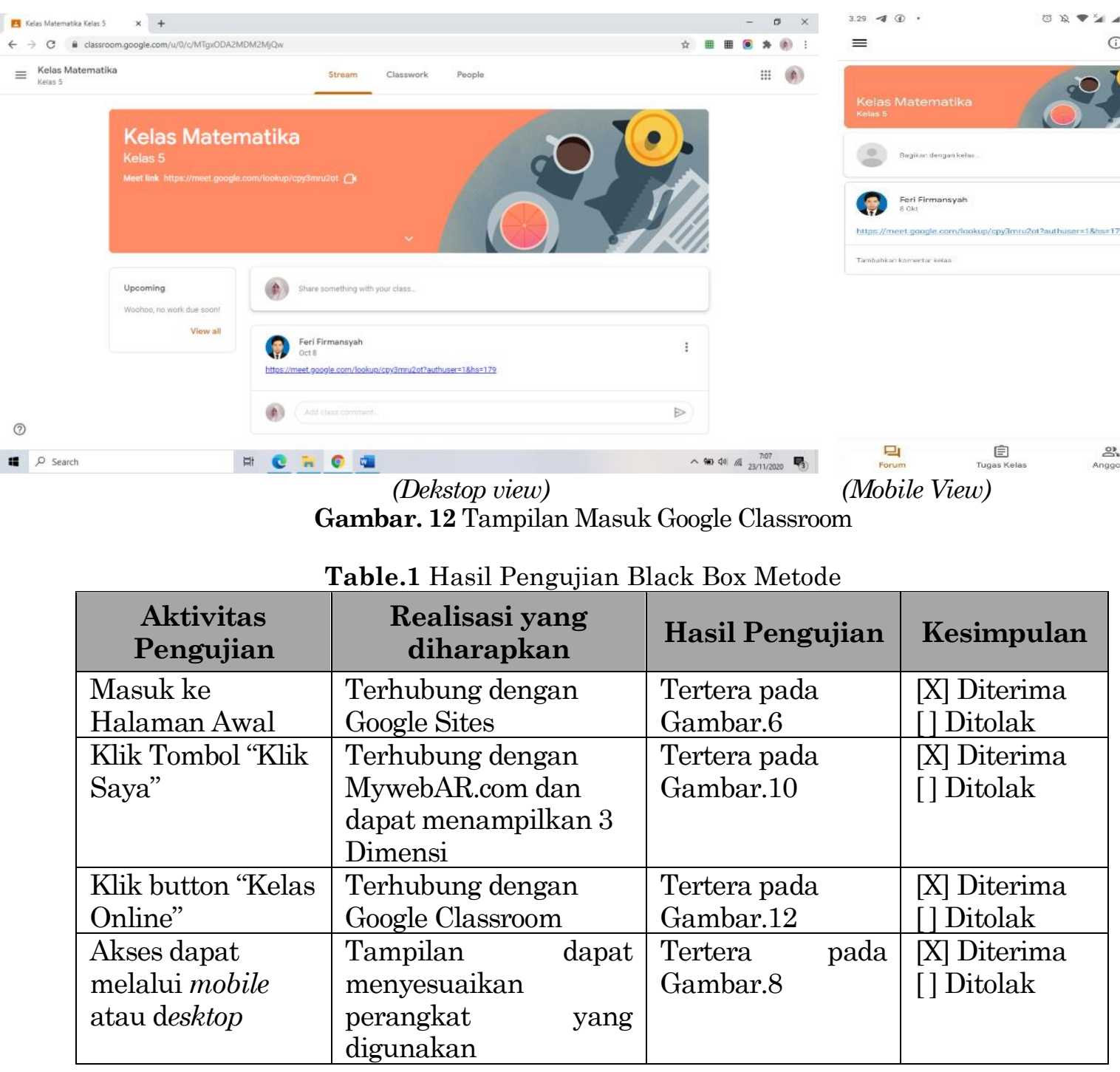


Hasil dari pengujian dengan black box yaitu pada halaman awal akan terhubung dengan google sites, Tombol "Klik Saya" pada subtopik materi pembelajaran akan terhubung dengan MywebAR.com untuk manampilkan bangun ruang dengan 3 dimensi, button "Kelas Online" akan terhubung ke Google Classroom untuk melanjutkan pembelajaran, dan untuk akses dapat melalui mobile dan Desktop disesuaikan dengan perangkat yang digunakan.

\section{Simpulan}

Dengan media pembelajaran berbasis digital ini dapat membantu siswa dan guru untuk melakukan proses pembelajaran secara online. Pengembangan media ini juga tidak terlalu sulit bagi guru sehingga diharapkan guru dapat secara mandiri mengembangkan media berbasis augmented reality ini secara mandiri dan memudahkan siswa dalam memahami materi bangun ruang atau materi lainnya melalui simulasi berbasis augmented reality yang dapat dibuat secara online dan diakses langsung dalam media pembelajaran digital ini. Untuk kegiatan selanjutnya akan dilanjutkan di penelitan inovasi model pembelajaran terbuka dan jarak jauh dan akan didiseminasikan pada seminar publikasi di tingkat nasional.

\section{Daftar Pustaka}

1. Ahmad, Intan. 2018. Proses Pembelajaran Digital dalam Era Revolusi Industri 4.0. Medan Ristekdikti.

2. Arsyad, Azhar. 2014. Media Pembelajaran. Jakarta: PT Rajagrafindo Persada.

3. Augustianingrum, N. K., \& Padmasari, A. C. Implementasi Algoritma Decision Tree Boardgame Dwipantara sebagai Media Pembelajaran Sejarah Kerajaan untuk Meningkatkan Minat Belajar Siswa SD. Edsence: Jurnal Pendidikan Multimedia, 2(1), 57-64.

4. Dale, E. 1969. Audiovisual methods in teaching (3rd edition). New York. Dryden Press.

5. Hanum, N. S. 2013. Keefektifan E-Learing Sebagai Media Pembelajaran (Studi Evaluasi Model Pembelajaran E-Learning SMK Telkom Sandhy Putra Purwokerto). Jurnal Pendidikan Vokasi, 3(1), 90102. https://doi.org/10.21831/jpv.v3i1.1584.

6. Hartanto, W. 2016. Penggunaan E-Learning Sebagai Media Pembelajaran. Jurnal Pendidikan ekonomi, 10(1), $1-18$.

7. Ibrahim, D. S., \& Suardiman, S. P. 2014. Pengaruh Penggunaan E-Learning Terhadap Motivasi dan Prestasi Belajar Matematika Siswa SD Negeri Tahunan Yogyakarta. Jurnal Prima Edukasia, 2(1), 66. https://doi.org/10.21831/jpe.v2i1.2645.

8. Jaya, T. S. 2018. Pengujian Aplikasi Dengan Metode Blackbox Testing Boundary Value Analysis ( Studi Kasus: K antor Digital Politeknik Negeri Lampung). Jurnal Informatika : Jurnal Pengembangan IT (JPIT), 03(02), $45-48$.

9. O’Malley, C. 2003. Guidelines for learning/Teaching/Tutoring in Mobile Environment.

10. Prihandoyo, M.T. 2018. Unified Modeling Language (UML) Model Untuk Pengembangan Sistem Informasi Akademik Berbasis Web. Jurnal Informatika: Jurnal Pengembangan IT (JPIT) Vol. 03 No. 01. Halaman 126.

11. Puspitasari, P., Sari, P., Putri, J., \& Wuryani, W. (2018). Pengaruh Penggunaan Media Pembelajaran terhadap Motivasi Belajar Mahasiswa IKIP Siliwangi. Parole: Jurnal Pendidikan
Bahasa
Dan
Sastra
Indonesia,
$1(2)$
$227-232$.

https://doi.org/http://dx.doi.org/10.22460/p.v1i2p\%25p.243.

12. Sagala, J.R. 2018. MODEL RAPID APPLICATION DEVELOPMENT (RAD) DALAM PENGEMBANGAN SISTEM INFORMASI PENJADWALAN BELAJAR MENGAJAR. Jurnal Mantik Penusa Vol. 2 No. 1. Halaman 88. 
13. Sari, I. P., Kartina, A. H., Pratiwi, A. M., Oktariana, F., Nasrulloh, M. F., \& Zain, S. A. Implementasi Metode Pendekatan Design Thinking dalam Pembuatan Aplikasi Happy Class di Kampus UPI Cibiru. Edsence: Jurnal Pendidikan Multimedia, 2(1), 45-55.

14. Suharyadi, dan S. K. Purwanto,2009, Statistika: Untuk Ekonomi dan Keuangan Modern, Edisi 2, Buku 1, Penerbit Salemba Empat, Jakarta. Halaman 25-39.

15. Sylviani, S., \& Permana, F. C. (2019). Pembelajaran Matematika Tingkat Sekolah Dasar Menggunakan Aplikasi Geogebra sebagai Alat Bantu Siswa dalam Memahami Materi Geometri. Edsence: Jurnal Pendidikan Multimedia, 1(1), 1-8.

16. Tosepu, Yusrin. Digitalisasi Pendidikan: Telaah Dunia Pendidikan menuju Transformasi Digital. Makasar : LSP3I. Accessed on : academia.edu.

17. Tosepu, Yusrin. Tantangan di Era Revolusi Industri 4.0 dan Implementasi Kebijakan Pembelajaran Berbasis Penelitian di Perguruan Tinggi. Makasar: LSP3I. Accessed on: academia.edu.

18. Trisnaningsih, S dkk. 2016. PENGEMBANGAN LEARNING MANAGEMENT SYSTEM QUIPPER SCHOOL PADA PEMBELAJARAN MATERI SISTEM PERTAHANAN TUBUH UNTUK MENINGKATKAN MOTIVASI DAN HASI BELAJAR SISWA KELAS XI DI SMA NEGERI 3 YOGYAKARTA. Jurnal Pendidikan Biologi, 5(6), 29-30.

19. Urora,A., \& Effendi, H. 2019. Pengaruh Penggunaan Media Pembelajaran E-Learning terhadap Motivasi Belajar Mahasiswa di Universitas Negeri Padang. JTEV (Jurnal Teknik Elekto Dan Vokasional), 05(02), 11-16. 